\title{
Non-Neoplastic Vision Disorder
}

National Cancer Institute

\section{Source}

National Cancer Institute. Non-Neoplastic Vision Disorder. NCI Thesaurus. Code C53534.

A non-neoplastic disorder that causes a disturbance in normal vision. Representative examples include amblyopia, astigmatism, myopia, and cataracts. 